\title{
Assessment of Noise Pollution in the Ashuganj Fertilizer Industrial Area, Ashuganj
}

\author{
M. S. Sultana*a, N. Jahan ${ }^{a}$, M. S. Islam ${ }^{b}$ and S. M. Masum ${ }^{c}$ \\ ${ }^{a}$ Department of Environmental Sciences, Jahangirnagar University, Savar, Dhaka. ${ }^{b}$ Analytical Research \\ Division, Bangladesh Council of Scientific and Industrial Research (BCSIR) Laboratories, Dhaka. ${ }^{c}$ Department \\ of Applied Chemistry and Chemical Engineering, University of Dhaka, Bangladesh
}

\begin{abstract}
Noise pollution in industries is now a serious environmental concern in Bangladesh. In this study sound levels are observed inside the Ashuganj Fertilizer Company Ltd (AFCL) Ashuganj. Continuous running of high speed turbo machinery, vibration of pipelines and structures, transmission of high pressure gas, sudden release of high pressure gas generate noise hazard inside the factory during the time of production. The sound level data was collected at seventeen different locations in the ammonia production plant, ten different locations in the urea production plant and ten different locations in the residential area of AFCL. In the ammonia plant, significantly high level of sound was observed $(>90 \mathrm{~dB})$ from the process gas cooler, let-down station, boiler-feed water pump, synthesis-gas compressor, process air compressor, alternator and ammonia compressor areas. In the Urea plant, Prill tower (top), Prill tower (absorber vent) are the most noise vulnerable areas with sound level $>90 \mathrm{~dB}$. Residential area found less affected by noise pollution (43-53 dB) but in some areas like playground, main gate of the residential area sound level sometimes cross the standard sound level of residential area ( $50 \mathrm{~dB})$. In the ammonia and urea plant, the sound levels are much higher than the standard sound level $(75 \mathrm{~dB})$ for the industrial area, which is considered a hazard of noise may induce hearing loss, annoyance and other adverse effects on the health of the workers of AFCL. Therefore, some remedial measures should be taken to reduce the sound level inside the factory.
\end{abstract}

Key words: Noise pollution, Ashuganj Fertilizer Company Ltd (AFCL), Ammonia production plant, Urea production plant, Sound level, Health hazard.

\section{Introduction}

Now a day's noise pollution is one of the biggest problems that the world is facing. The noise originates from human activities, especially the urbanization and the development of transport and industry. But noise pollution did not create much public concern due to ignorance. It is, along with other types of pollution has become a hazard to quality of life.

Kiernan (1997) finds that even relatively low levels of noise affect human health adversely. It may cause hypertension, disrupt sleep and/or hinder cognitive development in children. The effects of excessive noise could be cause a permanent loss of memory or a psychiatric disorder ( Babis et.al, 1993).

Noise may not seem as harmful as the contamination of air or water, but it is a pollution problem that affects human health and can contribute to a general deterioration of environmental quality. (DSilva, 2007). In a word, noise is just

\footnotetext{
* Corresponding author: E-mail:mahfuzasharifa@yahoo.com
}

unpleasent sound. The quality of unpleasentness of sound waves have been found to depend upon one or more of the following factors such as industrial generator sets, boilers, plant operations, trolley movement, transport vehicles, pumps, motors etc. With the progress in industrial growth, the level of noise has been increasing continuously. (Makenzie and David, 1998):

Heavy industries like shipbuilding and iron and steel have long been associated with Noise Induced Hearing Loss (NIHL). In most developing countries, industrial noise levels are higher than those in developed countries. Examples of industrial premises: heavy industrial and manufacturing premises, light industrial premises ,agricultural activities.

Industrial Noise Pollution is becoming a nuisance and measures have to be taken to control it or at least reduce it. It is hampering the physical and mental health of the workers and 
is alienating them from society. This is posing to be a challenge with very passing day and is a threat to safety and health of the people who are working in the industry and common people alike. It has been scientifically proved that noise more than 85 decibels can cause hearing impairment and does not meet the standards set for healthy working environment. The problem has been viewed and analyzed from all the perspectives but the solution probably is not so easy to achieve since there is a lot of contradiction between legislation, guidance and documents. Industrial Noise resulting to noise pollution has many reasons such as industries being close to human habitats which prevent the noise from decaying before it reaches human ear.

Noise pollution is not only a problem in the developed countries (Peterson, 1983, Brainard et.al, 2004, Nijs et.al, 2004); it is also a problem for developing countries like Bangladesh (Dey, et.al, 2002, Sing, et.al, 2004 and Uddin, et.al, 2009).
In Bangladesh main sources of noise pollution are the road traffics, industries, loud speakers, and electrical appliances. Industrial noise is becoming a big source of noise pollution in our country. In most of the industries standards for sound level are not maintained. For this workers are at threats for various types of effects that occur due to noise pollution.

Bangladesh is an agro-based industrially developing country of Asia. For the development of agriculture sector fertilizer factories plays an important role. Under the Bangladesh Chemical Industries Corporation (BCIC) there are 6 urea fertilizer factories in Bangladesh. Ashuganj Fertilizer Company Limited is one of them. This is one of the biggest fertilizer factories in our country. Production process of fertilizer is very complex. Large amounts of chemical are used in different steps of the production of fertilizer. As a result huge amount of effluents are discharged from the factory. Heavy noise is also a common feature inside the factory in the time

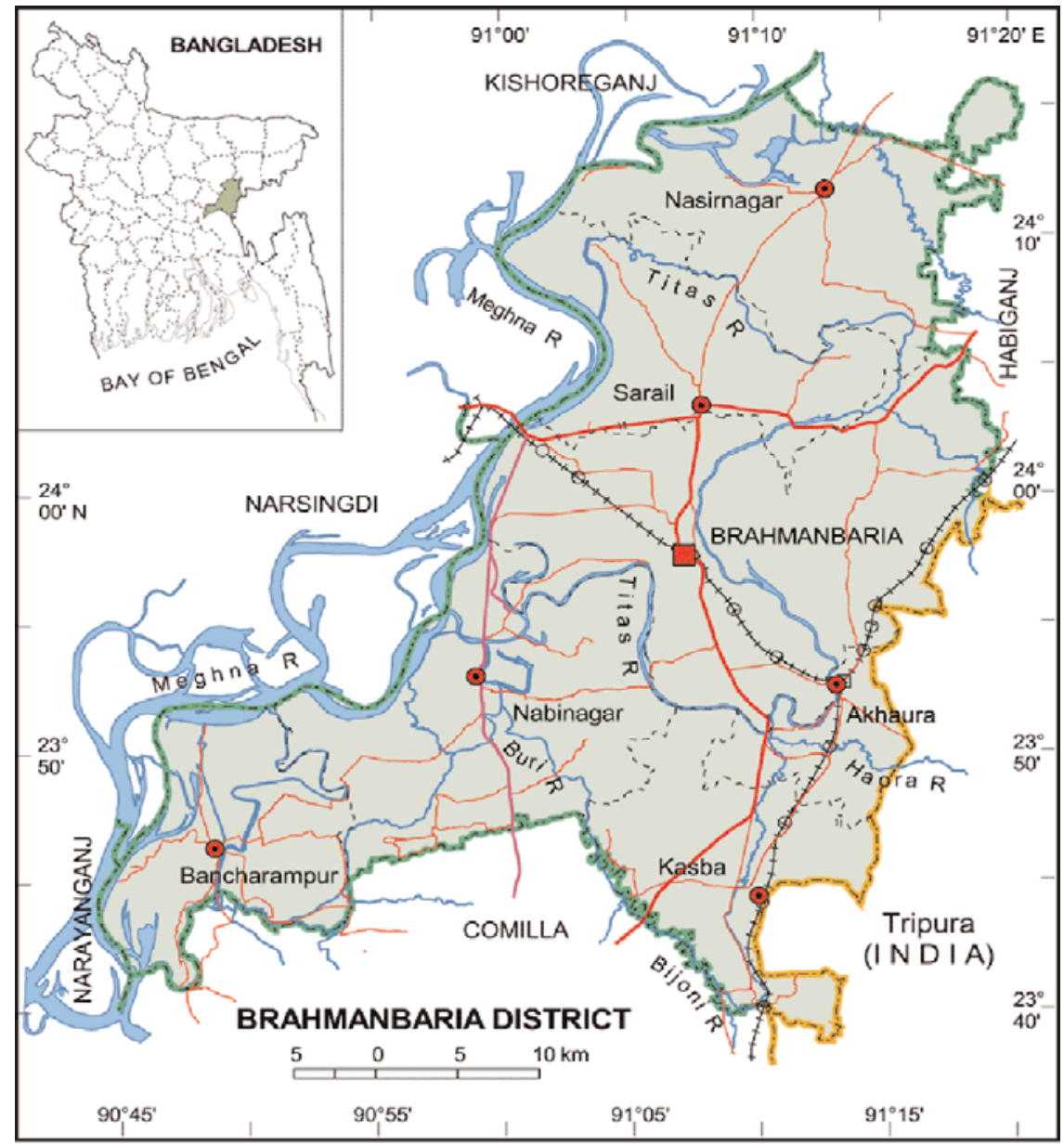

Fig. 1: Location of the study area. 
of production. This report mainly highlight on the production process and noise pollution inside the Ashuganj Fertilizer Company Limited.

The objective of this study is to gain a brief overview about the production process of Asuganj Fertilizer Company Limited and pollution related with the process. This paper is prepared mainly on the noise pollution of the factory. Noise pollution occurs inside the factory in the time of production due to continuous running of high-speed turbo machineries, transmission of high-pressure gas, vibration of pipelines and structures, sudden release of high-pressure gas etc. This work will help the authority to take steps against this problem.

\section{Methodology}

\section{Location of the study area}

Ashuganj Fertilizer Company Limited (AFCL) is situated on the east bank of river Meghna about $2 \mathrm{~km}$ south of Aahuganj railway station in the district of Brahmanbaria, Bangladesh approximately $100 \mathrm{~km}$ north of Dhaka (Fig.1). The factory is connected to Dhaka city and other parts of the country by road, river and rail.

\section{Company Background}

Aahuganj Fertilizer Company Limited was established by the Ministry of Industries (MOI) of Government of Bangladesh (GOB). For establishment of the factory the main contractor was Foster Wheeler Limited, UK and commissioned on 15th December, 1981. Later on the $1 \mathrm{st}$ December, 1983 the factory was handed over to Bangladesh Chemical Industries Corporation (BCIC). Since then AFCL has been operated as an enterprise of BCIC. Mainly urea is produced in this factory.

\section{Sample collection}

This study is divided into two main parts, one is the production process of fertilizer and another is the determination of sound level inside the factory. First part is prepared based on the site visit and the information (primary \& secondary) supplied by the authority of Ashuganj Fertilizer Company Limited (Ali, 2001). In the second part the noise level inside the factory was measured. For this, the study area was divided into 3 locations and the samples were collected from these areas.

1) Ammonia plant.

2) Urea plant.

3) Residential area.
The data in every location was taken in two different times of the day.

These are:

* Morning (9.00am-11.00am),

* Evening (5.00pm-7.00pm).

The data was taken in two different days for verifying the data. At every location data was taken in several points. Each point are identified by different location ID's ( Table I a, I b and Ic).

\section{Table Ia: Locations of the sampling sites of ammonia} production plant with ID numbers

\begin{tabular}{l|c|c}
\hline $\begin{array}{l}\text { Sample } \\
\text { No. }\end{array}$ & $\begin{array}{c}\text { Location's } \\
\text { ID }\end{array}$ & Sampling Locations \\
\hline 01 & AM-1 & Benfield Section Area \\
02 & AM-2 & Absorber-Desorber \\
03 & AM-3 & Primary Reformer \\
04 & AM-4 & Secondary Reformer \\
05 & AM-5 & Process Gas Cooler \\
06 & AM-6 & SNC Boiler Area \\
07 & AM-7 & SNC Boiler ID Fom \\
08 & AM-8 & Nock Out Drum \\
09 & AM-9 & Let Down Station \\
10 & AM-10 & Synthesis Gas Compressor (1st floor) \\
11 & AM-11 & NH $_{3}$ Compressor (1st floor) \\
12 & AM-12 & NH $_{3}$ Compressor (ground floor) \\
13 & AM-13 & Process Air Compressor (1st floor) \\
14 & AM-14 & Alternator-1 (1st floor) \\
15 & AM-15 & Alternator-2 (1st floor) \\
16 & AM-16 & CO $_{2}$ Compressor (1st floor) \\
17 & AM-17 & Boiler Feed Water Pump \\
\hline
\end{tabular}

Table Ib: Locations of the sampling sites of urea production plant with ID numbers

\begin{tabular}{l|c|c}
\hline $\begin{array}{l}\text { Sample } \\
\text { No. }\end{array}$ & $\begin{array}{c}\text { Location's } \\
\text { ID }\end{array}$ & Sampling Locations \\
\hline 01 & UR-1 & High Pressure Carb Pump \\
02 & UR-2 & High Pressure NH Nump $_{3}$ Prill Tower (ground floor) \\
03 & UR-3 & Prill Tower (blower floor) \\
04 & UR-4 & Prill Trill Tower (south) \\
05 & UR-5 & Prill Tower (west) \\
06 & UR-6 & Pump House (east) \\
07 & UR-7 & Prill Tower (absorber vent) \\
08 & UR-8 & Prill Tower (top) \\
09 & UR-9 & Urea Plant (1st floor) \\
10 & UR-10 &
\end{tabular}


Table Ic: Locations of the sampling sites of residential area of AFLC with ID numbers

\begin{tabular}{l|c|c}
\hline $\begin{array}{l}\text { Sample } \\
\text { No. }\end{array}$ & $\begin{array}{c}\text { Location's } \\
\text { ID }\end{array}$ & Sampling Locations \\
\hline 01 & RS-1 & Suth-West side of the residential area \\
02 & RS-2 & In front of store \\
03 & RS-3 & Main gate of the residential area \\
04 & RS-4 & In front of school \\
05 & RS-5 & Playground \\
06 & RS-6 & Water tank \\
07 & RS-7 & Employ's club \\
08 & RS-8 & South-East corner of residential area \\
09 & RS-9 & Infront of Mosque \\
10 & RS-10 & In front of Hospital \\
\hline
\end{tabular}

\section{Noise measurement}

It is common international practice to determine noise in terms of levels, which are expressed as a logarithmic function of the sound pressure and adapted to the sensitivity of the human ear. It can be defined as:

Sound pressure level $(\mathrm{SPL})=20 \log _{10} \mathrm{P} / \mathrm{P}_{0} \mathrm{~dB}$

Where, $P$ is the pressure variation measured in $N / \mathrm{m}^{2}$, and $P_{0}$ is the standard reference pressure taken as $2 \times 10^{-5} \mathrm{~N} / \mathrm{m}^{2}$.

Four descriptors are used to determine the impact of environmental noise on public health. These are: The A-weighted
Sound Level, A-weighted Sound Exposure Level, Equivalent Sound Level, Day-Night Average Sound level (David el al, 1997, Cavanaugh and Tocci, 1998). In this paper, A ST-8850 digital sound level meter was used to measure the A-weighted Sound Level. The sound level data for different location for different specified time of a day was collected. The three readings of sound level in different locations were taken and the average of the three readings was calculated.

\section{Results and Discussion \\ Production Processes of Ammonia and Urea}

Natural gas is the main raw material for production of urea and ammonia. Natural gas comes from the Titas gas field via filters and metering station, enters into the desulphurization unit. Here, sulfur compounds are removed by catalytic reactions. Then the gas is cracked by steam in the primary and secondary reformers to produce carbon dioxide, carbon monoxide and hydrogen. Moreover, air is also added to the secondary reformer as a source of nitrogen.

\section{Process Description of ammonia plant}

For the production of Ammonia following steps are involved in AFCL:

1) Desulphurization, 2) Reforming, 3) CO- Shift Conversion, 4) $\mathrm{CO}_{2}$ Removal 5) Methanator, 6) Compression, 7) Ammonia Synthesis, 8) Refrigeration.

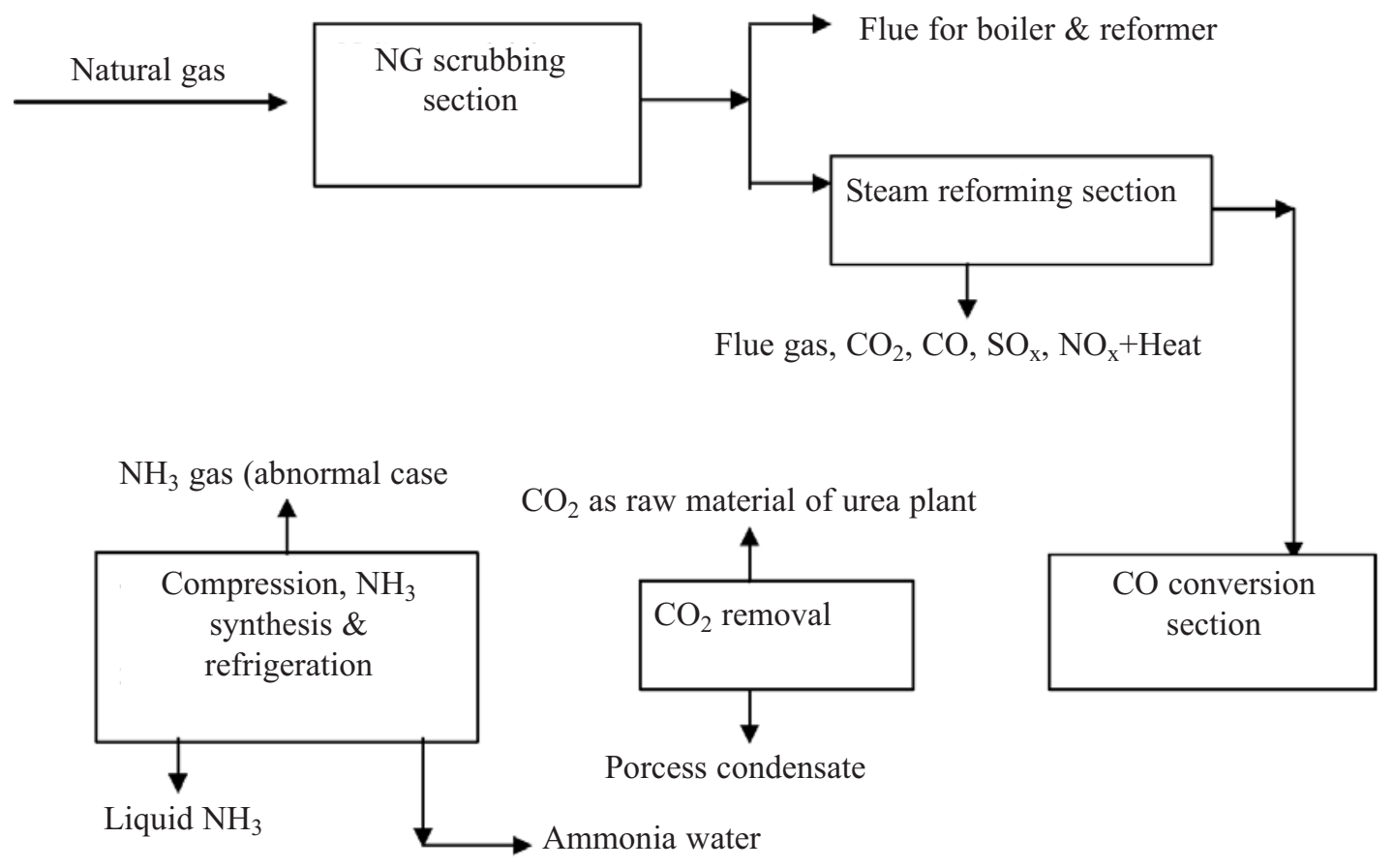

Fig. 2: Block diagram of ammonia plant 


\section{Process Description of Urea plant}

Urea is produced from liquid ammonia and gaseous carbon dioxide at $170-190^{\circ} \mathrm{C}$ temperature and $135-145$ bar pressure. This is done by two steps of reaction.

1st step: $2 \mathrm{NH}_{3}(\mathrm{~g})+\mathrm{CO}_{2}(\mathrm{~g})=\mathrm{NH}_{4}-\mathrm{COO}-\mathrm{NH}_{2}$

$\Delta \mathrm{H}=-28 \mathrm{Kcal} / \mathrm{mole}, \mathrm{Temp}: 180^{\circ} \mathrm{C}$.

2nd step: $\mathrm{NH}_{4}-\mathrm{COO}-\mathrm{NH}_{2}+\mathrm{H}_{2} \mathrm{O}$ (dehydration reaction)

$\Delta \mathrm{H}=3-4 \mathrm{Kcal} / \mathrm{mole}$, Temp: $180^{\circ} \mathrm{C}$.

Steps of urea production are as follows: 1) $\mathrm{NH}_{3}$ and $\mathrm{CO}_{2}$ compression, 2) Synthesis and high pressure recovery, 3) Recalculation, 4) Evaporation and Priling.

\section{Noise pollution of ammonia plant}

Ammonia plant is a big plant. Large machineries are used here. These machines are placed near to one another. Loud noise produced from these machines. The plant has big machines; these are synthesis gas compressor, ammonia compressor, process air compressor, alternator- $1 \& 2$ etc. (fig. 4). These machines produce high volume of noise, from $80 \mathrm{~dB}$ to around $100 \mathrm{~dB}$ and vibration occurs in this place due to high volume of sound. It is found that almost all the sound data of different locations of the ammonia plant exceeds the standard sound level for industrial area $(75 \mathrm{~dB})$.

Sound levels have been measured in the ammonia plant in two consecutive days during morning (9.00am-11.00am) and

Vent after abs

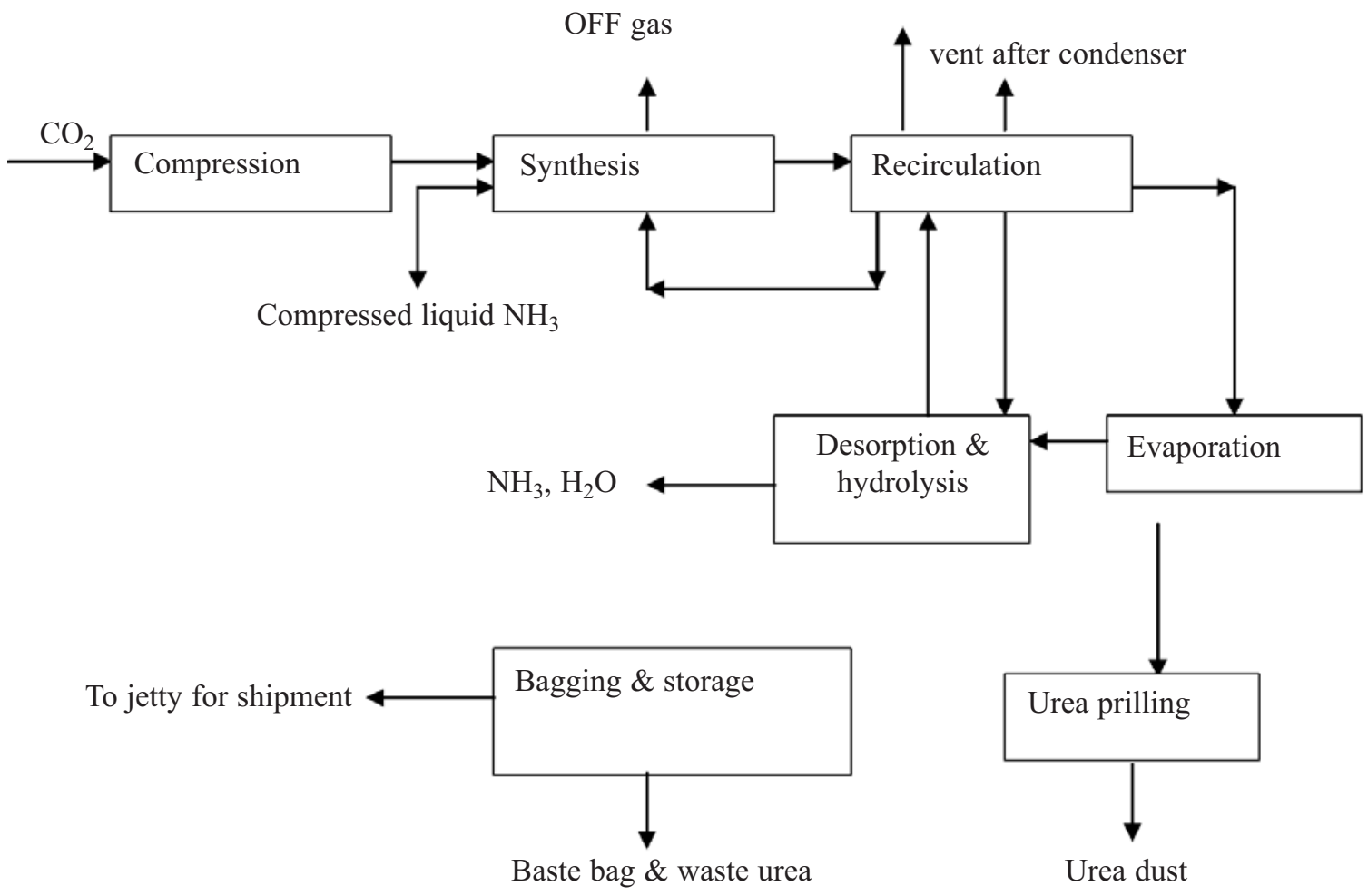

Fig. 3: Block diagram of urea plant

\section{Noise Hazard of the production process}

Noise level is very high inside the factory in the time of production. Continuous running of high speed turbo machinery, vibration of pipe lines and structures, transmission of high pressure gas, sudden release of high pressure gas generate noise hazard inside the factory in the time of production. evening (5.00pm-7.00pm). Average sound level of different locations in the ammonia plant is given in the Table II. From this table it is seen that in the morning highest sound (93.18 $\mathrm{dB})$ is observed from the Let-down station area and lowest sound $(80.00 \mathrm{~dB})$ is observed from the Absorber-desorber section. In the evening sound level is also high inside the ammonia plant. From the Table II, it is found that in the 

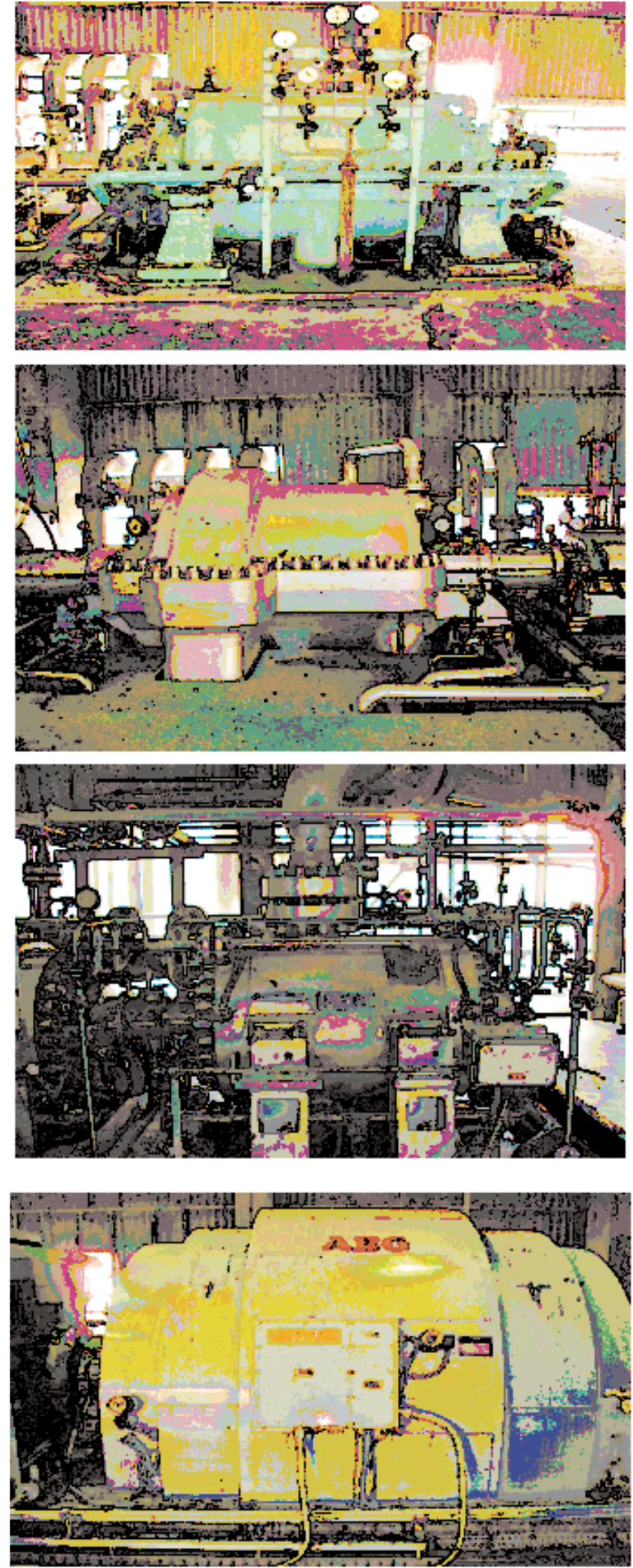

Fig. 4: Machineries of AFCL that causes noise pollution
Table II: The variation of sound level in ammonia plant with the sampling locations

\begin{tabular}{l|l|l|c|c}
\hline \multirow{2}{*}{$\begin{array}{l}\text { Sample } \\
\text { No. }\end{array}$} & Location's & \multicolumn{2}{|c|}{ Sound Level(dB) } & $\begin{array}{c}\text { Standard sound } \\
\text { level }(\mathrm{dB}) \text { for } \\
\text { industrial area }\end{array}$ \\
\cline { 3 - 4 } & & Morning & Evening & ind5 \\
\hline 01 & AM-1 & 83.84 & 80.38 & 75 \\
02 & AM-2 & 80.00 & 79.70 & 75 \\
03 & AM-3 & 85.13 & 82.27 & 75 \\
04 & AM-4 & 85.10 & 82.08 & 75 \\
05 & AM-5 & 90.05 & 87.48 & 75 \\
06 & AM-6 & 84.43 & 83.43 & 75 \\
07 & AM-7 & 86.73 & 85.31 & 75 \\
08 & AM-8 & 80.31 & 79.78 & 75 \\
09 & AM-9 & 93.18 & 88.63 & 75 \\
10 & AM-10 & 88.41 & 87.95 & 75 \\
11 & AM-11 & 88.25 & 88.03 & 75 \\
12 & AM-12 & 87.74 & 88.62 & 75 \\
13 & AM-13 & 89.81 & 88.70 & 75 \\
14 & AM-14 & 89.16 & 87.78 & 75 \\
15 & AM-15 & 88.50 & 86.65 & 75 \\
16 & AM-16 & 88.40 & 87.26 & 75 \\
17 & AM-17 & 90.71 & 90.23 & \\
\hline
\end{tabular}

evening highest sound ( $90.23 \mathrm{~dB}$ ) is observed from the Boiler feed water pump section and lowest sound $(78.70 \mathrm{~dB})$ is observed from the Absorber-desorber section. Comparison of sound levels that are measured in the morning and evening is also given in figure 5. It is found that sound level is slightly higher in the morning than in the evening in many sampling locations. These differences may be due to wind or leakage in pipes and joints.

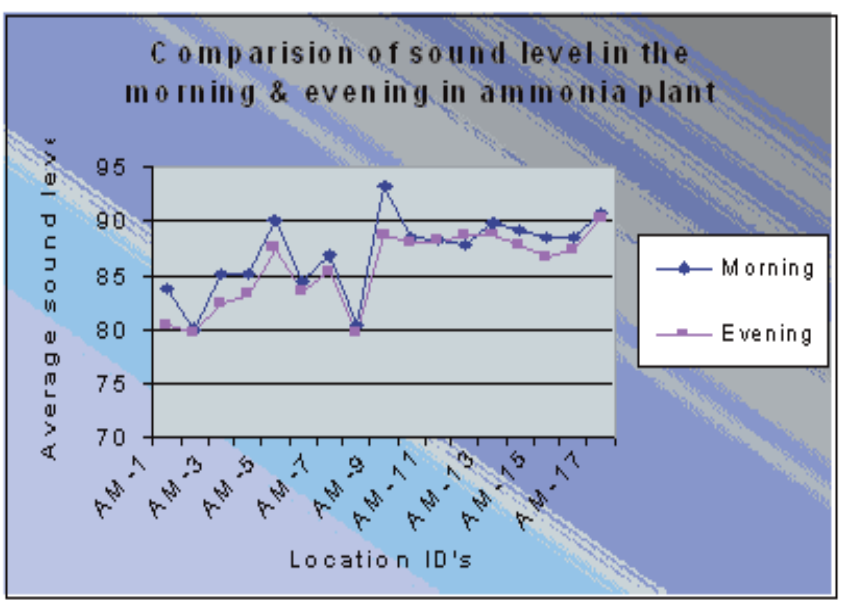

Fig. 5: Comparison of sound levels between moning and evening in the ammonia plant 


\section{Noise pollution of urea plant}

Urea plant is smaller than Ammonia plant. Averages of sound level in the urea plant that are measured in two consecutive days are given in the Table III From this table it is seen that, in the morning highest sound level observed from the Prill tower (top) and the sound level is $97.21 \mathrm{~dB}$. Lowest sound level $(79.78 \mathrm{~dB})$ is observed from the Prill tower (ground floor). Further from the Table III, it is found that in the evening highest sound $(97.41 \mathrm{~dB})$ observed from the Prill tower (top) and lowest sound $(79.43 \mathrm{~dB}$ ) observed from the Prill tower (south). In the urea plant highest sound always observed from the Prill tower (top). This may be due to heavy machines that are placed in this area and for wind speed. Some locations like Prill tower (ground floor) and Prill tower (south) are less noisy than any other locations in the plant because these areas are not surrounded by different types of heavy machines.

Table III: The variation of sound level in urea plant with the sampling locations

\begin{tabular}{l|c|l|l|c}
\hline $\begin{array}{l}\text { Sample } \\
\text { No. }\end{array}$ & $\begin{array}{c}\text { Location's } \\
\text { ID }\end{array}$ & \multicolumn{2}{|c|}{ Sound Level(dB) } & $\begin{array}{c}\text { Standard sound } \\
\text { level (dB) for } \\
\text { industrial area }\end{array}$ \\
\cline { 3 - 5 } & & Morning & Evening & 75 \\
01 & UR-1 & 86.83 & 86.00 & 75 \\
02 & UR-2 & 88.26 & 85.76 & 75 \\
03 & UR-3 & 79.78 & 80.68 & 75 \\
04 & UR-4 & 82.79 & 84.45 & 75 \\
05 & UR-5 & 80.63 & 79.43 & 75 \\
06 & UR-6 & 82.07 & 81.26 & 75 \\
07 & UR-7 & 85.14 & 81.08 & 75 \\
08 & UR-8 & 93.98 & 93.51 & 75 \\
09 & UR-9 & 97.21 & 97.41 & 75 \\
10 & UR-10 & 84.25 & 83.98 & \\
\hline
\end{tabular}

The comparison of sound levels on morning and evening in urea plant are presented in figure-6. Similar sound levels have been observed during morning and evening in the urea plant. However, all of the sound level data of urea plant exceeds the standard sound level for the industrial area (75 $\mathrm{dB})$.

\section{The impact of noise pollution on the residential area}

Like ammonia and urea plant, in the residential area sound levels have been also measured in two consecutive days during morning and evening. In this area sound levels are measured from 10 sampling locations.

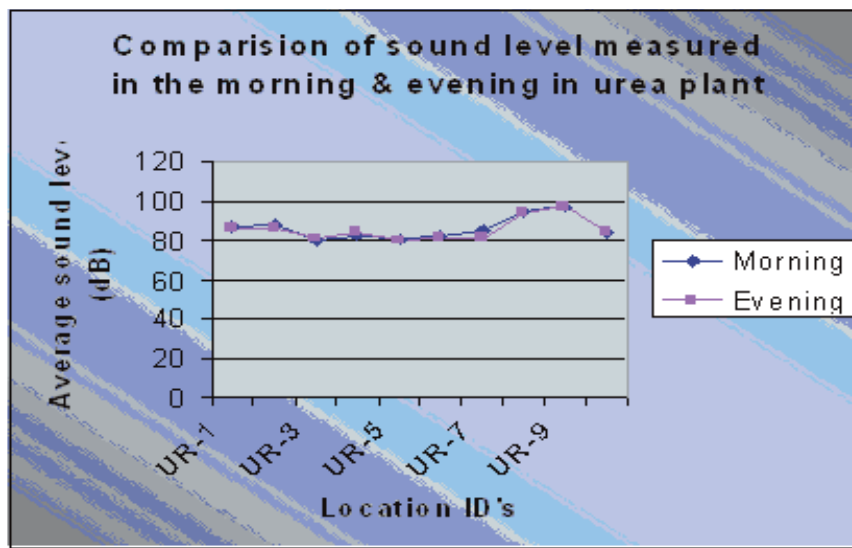

Fig. 6: Comparison of sound levels between morning and evening in urea plant

Averages of sound levels that are observed from the residential area in morning and evening in two consecutive days are given in the Table IV. In the morning highest sound in this area is observed $51.38 \mathrm{~dB}$ from the playground and lowest sound $(43.13 \mathrm{~dB})$ is observed from the south-west side of the residential area. There are some differences in sound level in the evening than in the morning. In the evening highest sound $(53.48 \mathrm{~dB})$ is observed from the playground and lowest sound $(44.50 \mathrm{~dB})$ is observed from the south- east corner of the residential area. A comparison of sound level in morning $\&$ evening are given in figure 7 . Similar sound levels have been observed during morning and evening in the residential area. Here it is noted that the distance of the residential area is more than $1 \mathrm{~km}$ from the factory. As a result this area is not so much noisy as inside the factory. But in some places sound level exceeds the standard level $(50 \mathrm{~dB})$ for the residential area.

Table IV: The variation of sound level in Residential urea with the sampling locations

\begin{tabular}{l|c|l|l|c}
\hline \multirow{2}{*}{$\begin{array}{l}\text { Sample } \\
\text { No. }\end{array}$} & $\begin{array}{c}\text { Location's } \\
\text { ID }\end{array}$ & \multicolumn{2}{|c|}{ Sound Level(dB) } & \begin{tabular}{c} 
Standard sound \\
level $(\mathrm{dB})$ for \\
\cline { 3 - 4 }
\end{tabular} \\
\cline { 3 - 4 } & & Morning & Evening & Residential area \\
\hline 01 & RS-1 & 43.13 & 45.73 & 50 \\
02 & RS-2 & 45.85 & 49.08 & 50 \\
03 & RS-3 & 50.48 & 52.43 & 50 \\
04 & RS-4 & 49.33 & 52.56 & 50 \\
05 & RS-5 & 51.38 & 53.48 & 50 \\
06 & RS-6 & 50.96 & 48.38 & 50 \\
07 & RS-7 & 50.08 & 50.05 & 50 \\
08 & RS-8 & 47.86 & 44.50 & 50 \\
09 & RS-9 & 47.26 & 51.90 & 50 \\
10 & RS-10 & 47.46 & 46.88 & 50 \\
\hline
\end{tabular}




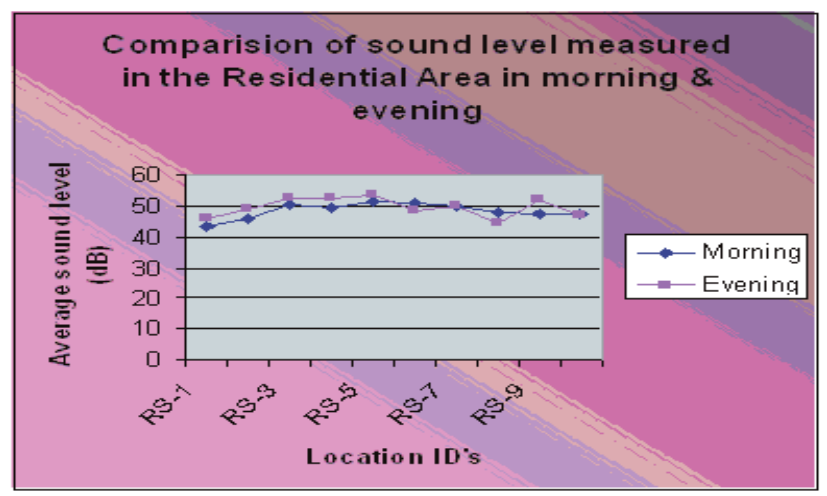

Fig. 7: Comparison of sound levels between morning and evening in the residential area.

\section{Conclusion}

Ashuganj Fertilizer Company Limited (AFCL) is a heavy chemical industry. This study is based on the noise pollution of this factory. Continuous running of high speed turbo machinery, vibration of pipelines and structures, transmission of high pressure gas, sudden release of high pressure gas generates noise hazard inside the factory in the time of production. But no data is available on the noise level inside and outside of the factory. This study will provide information to the authority about the present status of noise pollution in the factory. It should be mentioned that sound level inside the ammonia and urea plant is high. In the urea plant Prill tower is the most noise vulnerable area ( $100 \mathrm{~dB})$ and in the ammonia plant Let-down station, Alternators, Compressors like $\mathrm{NH}_{3}$ compressor, Process air compressor etc produce heavy noise (85-92 dB). High-pressure carb pump in the urea plant also produces sound more than $80 \mathrm{~dB}$. Therefore, in the ammonia and urea plant, the sound level is much higher than the standard sound level $(75 \mathrm{~dB})$ for the industrial area which is a hazard of noise induced hearing loss, annoyance and other adverse effects on the health of the workers of AFCL. But as the residential area is situated in $1 \mathrm{~km}$ distance from the factory high level of sound does not reach in this area. Distance act here as a barrier of noise. Much of the locations of the residential area have noise level around $50 \mathrm{~dB}$. Sometimes it is higher than $50 \mathrm{~dB}$. Proper maintenance of these machines will help to reduce the sound level inside the factory. Authority should take necessary steps to improve the condition.

\section{References}

Ali J., Ansari A. M. H. and Miah A. B. (2000-2001). Environmental Management System (EMS) Manual of Zia Fertilizer Company Limited, A BCIC-World Bank Joint Project.
Babish W., Ishing H., Elwood P. C., Sharp D. S. and Bainbton D (1993). Traffic Noise and Cardiovascular risk. Archives Environmental Health, 48: 406-413.

Brainard J. S., Andrew P., Jones Ian J., Bateman and Andrew A. Lovett (2004). Exposure to environmental urban noise pollution in Barmingham, UK, Urban Studies 41 (13): 2581-2600.

Cavanaugh W. C. and Tocci G. C. (1998). "Environmental Noise- The Invisible Pollutant", E.SC, 1(1): 1-5.

Dey A. R., Kabir N. and Efroymson D. (2002). Noise Pollution: Research and Action; Work for a Better Bangladesh.112-115.

Dcjoy N. M. (1984). A report on the status of research on the cardiovascular effects of noise.Y Control Er Journal, 23: 32-39.

David H. F. L, Bela G. L. and Bouis. P. A. (1997). Environmental Engineering Handbook (2nd edition), 1: 449-506.

DSilva N. V (2007). Noise Pollution, http:// www.buzzle.com.

Kierman V. (1997). Noise pollution robs kids of languages skills. New Scientists, 32-34.

Makenzia L. D. and David A. C. (1998). Introduction to Environmental Engineering (3rd edition), McGrawHill Series in Water Resources and Environmental Engineering, 550-629.

Nijs T. C., Niet R. D. and Commentuijn L. (2004). Constructing land use maps of the Netherlands in 2030, Journal of Environmental Management.72(1): 35-42.

Peterson Y. (1983). Speech the legibility of normal listeners and persons with impaired hearing in traffic noise. Journal of Sound Vibration.90: 341-360.

Sing N. and Davar S. C. (2004). Noise Pollution- Source, Effect and Control, J.Hum.Ecol, 16(3):181-187.

Uddin M. J., Rahman M. A. and Roy. R. (2009) Noise Mapping and their Interpretations of Sahbagh area, Dhaka, Bangladesh. J. of Env. Res. 7: 43-51.

Received : July 07, 2010;

Accepted : December 05, 2010 